UDK: 621.38:620.9

DOI: https://doi.org/10.24867/05BE46Stevanovic

\title{
BEZBEDONOSNI I INFORMACIONI SISTEM SOLARNIH ELEKTRANA SA PRORAČUNOM OSVETLJENJA
}

\section{SECURITY AND INFORMATION SYSTEM OF SOLAR PLANTS WITH LIGHTING CALCULATION}

\section{Aleksandra Stevanović, Vladimir Katić, Fakultet tehničkih nauka, Novi Sad}

\begin{abstract}
Oblast - ELEKTROTEHNIKA I RAČUNARSTVO
Kratak sadržaj - U radu je predstavljen opis bezbedonosnih i informacionih sistema, koje solarne FN elektrane treba da poseduju sa konkretnim primerima informacionih i bezbedonosnih sistema. Izvršena je uporedna analiza četiri softverska alata za projektovanje osvetljenja i dat je proračun za jednu solarnu elektranu. Na kraju je data tehno-ekonomska analiza.
\end{abstract}

Ključne reči: Solarne $F N$ elektrane, sigurnosni $i$ bezbedonsoni sistem, proračun osvetljenja

Abstract - In the paper description of security and information system for solar PV plants with examples of security and information systems is presented. Four softwares for lighting calculations are compared and lighting calculation for one solar plant is presented. Techno-economic analysis is given at the end.

Keywords: Solar plant, Security and Information system, lighting calculation

\section{UVOD}

Problem sigurnosti je aktuelna tema za solarne fotonaponske (FN) elektrane, kao i za druge distribuirane generatore. Ove elektrane se često nalaze na izolovanim područjima, koja su određena solarnim potencijalom, potrebnim prostorom i drugim pogodnostima, ali su time izložene značajnijim bezbedonosnim i operativnim rizicima. Postoji više rešenja za zaštitu ovakvih objekata, kao što su:

- video nadzor - postupak za prepoznavanje i procenu pokreta preko kamera i inteligentnog softvera, kao i aktiviranje alarma ako je potrebno.

- perimetrijska zaštita - zasnovana je na detekciji prisustva i kretanja ljudi unutar čuvanog prostora,

- ograđivanje električnom ogradom ili 3D panelima,

- sistemi za zaštitu pomoću mikrotalasa - jedinice ove zaštite sastoje se od predajnika i prijemnika koji su postavljeni jedan nasuprot drugom.

Na slici 1 data je ilustracija mogućih sistema za nadzor jedne solarne elektrane.

Pored sistema za zaštitu, potrebno je imati i informacioni sistem. Informacioni sistem prati performanse elektrane u cilju optimizacije proizvodnje i prevencije kvara. Sastoji se od senzora i mernih uređaja, koji prate i mere uslove

\section{NAPOMENA:}

Ovaj rad proistekao je iz master rada čiji mentor je bio dr Vladimir Katić, red. prof. sredine i izlaze panela. Pored senzora, postoje komunikacijski uređaji koji su povezani sa SCADA sistemom mrežnog invertora, a preko interneta i sa računarom za nadzor i sladištenje podataka.

Bitna karika u bezbedonosnom sistemu jedne solarne FN elektrane je njeno spoljno osvetljenje. Spoljašnje osvetljenje je neophodno u obezbeđivanju površina $i$ objekata od značaja u okviru postrojenja. Pod površinama od značaja podrazumevaju se FN paneli, transformator, objekat sa invertorima i objekat kontrolne sobe u kome se nalazi sistem za prikupljanje informacija sa senzora $\mathrm{i}$ mernih uređaja. Ako dođe do kvara bitno je osvetliti ove tačke solarne elektrane. Pored toga spoljašnje osvetljenje se koristi za unapređenje sigurnosti, jer iako se u okviru video nadzora koriste kamere sa infracrvenim reflektorima za noćno snimanje, osvetljenje površina daje jasniji i precizniji pogled. Postoji mogućnost korištenja osvetljenja sa senzorima pokreta $\mathrm{i}$ napajanjem iz obnovljivih izvora tj. pametnog osvetljenja, čime se smanjuju troškovi i produžuje vek korišćenja.

U ovom radu je urađena uporedna analiza četiri softverska alata za dizajniranje i proračun osvetljenja, koje je neophodno za nadzor i obezbeđivanje solarne elektrane. Od ta četiri softvera, kao najpovoljniji izabran je Relux za proračun osvetljenja jedne solarne elektrane, a na kraju je data tehno-ekonomska analiza.

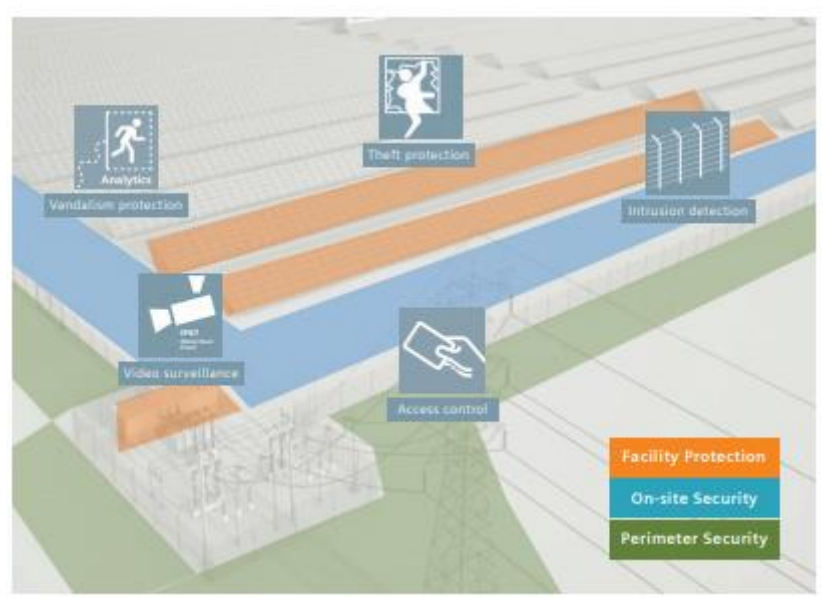

Slika1. Primer sistema za nadzora jedne solarne elektrane [1]

\section{UPOREDNA ANALIZA SOFTVERSKIH ALATA ZA PROJEKTOVANJE OSVETLJENJA}

Iako postoji više desetina programa za dizajniranje i proračun osvetljenja, svi su zasnovani na dva matema- 
tička algoritma: algoritam radiostatičnosti i algoritam zračenja. Dialux, Relux, AGI32 i Radiance su četiri najpopularnija softverska alata i nad njima je izvršena uporedna analiza. Svaki od ovih programa ima mane i vrline u odnosu na ostale. AGI32 daje najtačnije proračune, ali nije besplatan. Radiance, takođe daje izuzetno tačne proračune, ali nema korisnički pogodan interfejs. Dialux i Relux daje proračune slične tačnosti, ali je Relux za nijansu brži. Vreme trajanja simulacija u ovim programima dato je u tabeli 1. Relux je najbrži, a pored brzine, daje $i$ poprilično tačne rezultate $u$ svim situacijama. Pokazao se kao najpogodniji kada uvažimo njegov interfejs, izlazne izveštaje i podatke, efikasnost, podršku, koju pruža korisnicima i modelovanje u samom programu.

Tabela1. Vreme trajanja simulacija u četiri analizirana softverska alata za simulaciju osvetljenja [2]

\begin{tabular}{|c|c|c|c|c|}
\hline $\begin{array}{c}\text { Vreme trajanja } \\
\text { simulacije }\end{array}$ & $\begin{array}{c}\text { DIALux } \\
{[\mathrm{s}]}\end{array}$ & $\begin{array}{c}\text { Relux } \\
{[\mathrm{s}]}\end{array}$ & $\begin{array}{c}\text { AGI32 } \\
{[\mathrm{s}]}\end{array}$ & $\begin{array}{c}\text { Radiance } \\
{[\mathrm{s}]}\end{array}$ \\
\hline $\begin{array}{c}\text { Dnevno } \\
\text { osvetljenje }\end{array}$ & 70 & 10 & 24 & 193 \\
\hline $\begin{array}{c}\text { Dnevno i } \\
\text { veštačko } \\
\text { osvetljenje }\end{array}$ & 90 & 10 & 35 & 225 \\
\hline $\begin{array}{c}\text { Veštačko } \\
\text { osvetljenje }\end{array}$ & 8 & 5 & 10 & 53 \\
\hline
\end{tabular}

\section{OPIS RADA U RELUX-U I PRIMENA ZA DIZAJNIRANJE OSVETLJENJA SOLARNE FN ELEKTRANE}

\subsection{Postavka problema}

Za solarnu FN elektranu, koja će poslužiti za dizajniranje spoljnog osvetljenja uRelux-u uzeto je solarno postrojenje u Stolcu snage $150 \mathrm{~kW}$, koje zauzima $3.650 \mathrm{~m}^{2}$, ima 648 FN panela, raspoređenih u 4 celine (grupe). Svaka celina ima 9 nizova, a svaki niz sačinjen je od $18 \mathrm{FN}$ panela. Pored panela, na zemljištu gde se nalazi solarna elektrana, postoji i objekat za nadzor i razvodno postrojenje za povezivanje na mrežu.

\subsection{Projektovanje osvetljenja solarne FN elektrane}

Relux ima mogućnost da se unese CAD fajl enterijera, eksterijera, ulice ili tunela i uradi proračun osvetljenja ili da se crta posmatrani prostor direktno u programu. Za potrebe ovog projekta, nacrtan je plan postrojenja $u$ Aecosim softveru. Aecosim je program za crtanje ekvivalentan Autodesk-ovom AUTOCAD-u i Revit-u.

Nakon što je nacrtana solarna farma, potrebno je izvesti crtež u datoteku sa ekstenzijom .dwg jer je to ekstenzija koja može da se uveze u Relux. Sledeći korak je uvoz CAD datoteke u program za dizajniranje osvetljenja. S obzirom da se pomoću Relux-a može modelovati unutrašnje i spoljašnje osvetljenje potrebno je pri samom otvaranju izabrati koji tip osvetljenja se modeluje.

Zatim se unose osnovni podaci koji će biti ispisani u izveštaju. To su: broj projekta, naručilac/kupac projekta, ime projektantske firme, datum i kratak opis projeka. Posle ispunjavanja ovih podataka, uvozi se .dwg fajl i bira se koordinatni početak i razmera. Unesen je fajl u obliku 2D crteža. Zbog toga je potrebno sve objekte koji bi mogli bacati senku nacrtati u 3D obliku.
Pomoću opcija iz kartice INSERT na 2D planu nacrtana je ograda koja se nalazi oko postrojenja, objekat koji se nalazi u okviru solarne elektrane i razvodno postrojenje. To je nacrtano jer su to objekti od značaja za osvetljenje zbog bacanja senke i smanjivanje osvetljenosti područja.

Sledeći korak je izbor sijalica. Relux pruža korisniku veliku bazu podataka sa više od 80 proizvođača. Moguće je preuzeti sijalicu sa zvaničnog sajta proizvođača i uvesti je u program. Pored toga, moguće je pristupiti online bazi podataka, izabrati sijalicu i uvesti je. Sijalice se unose u projekat pomoću kartice Products iz linije alatki. Kada se uvezu, u Relux-u se vide detaljni podaci o datoj sijalici. Za potrebe ovog projekta, izabrana je LED sijalica proizvođa SITECO. Podaci o sijalicama se nalaze na slici 2. Na slici vidimo kolika je dimenzija reflektora, kolika je njegova efikasnost, koliko lumena daje, kakva je usmerenost svetlosti koju daje reflektor, koliko snage mu je potrebno, koje je boje svetlost koju daje reflektor.

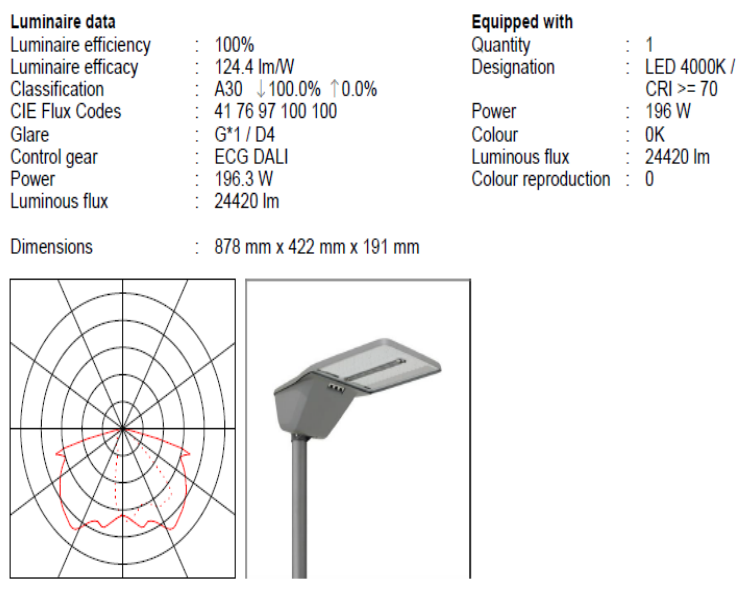

Slika 2. Podaci o izabranoj sijalici [3]

Kada se rasporede sijalice na željene pozicije i visinu, radi se proračun pomoću opcije "calculate" iz linije alatki. Moguće je podesiti faktor održavanja, visinu, nagibni ugao sijalice. Raspored sijalica i rezultat osvetljenje koje daju dat je na slici 3 .

Na slici 3 se vidi da sve površine, koje se nalaze u okolini ograde i svi putevi, koji se nalaze između FN panela imaju osveljenost preko 100 luksa, što daje dovoljnu vidljivost pri pokušaju provale ili pri eventualnom kvaru. Sve sijalice se nalaze na stubu visine $7 \mathrm{~m}$ sa uglom nagiba do 10 stepeni. Taj ugao ne sme biti veći zbog insekata koji bi udarali o svetleći deo reflektora i tako smanjivali svetlosnu moć. Uvažen je i faktor održavanja u vrednosti 0,8 zbog toga što snaga sijalice opada sa vremenom rada.Snaga koja je potrebna svim sijalicama je $3,7 \mathrm{~kW}$. Sve ove informacije i grafici se mogu odštampati u PDF formatu u formi izveštaju. Izveštaj može imati sadržaj, podatke o sijalicama, 2D/3D poglede sa osvetljenjem i bez i dr. Moguće je izabrati šta će se sve prikazati u izveštaju u zavisnosti od potreba korisnika, projekta i kupca. U Relux-u postoji mogućnost dinamičkog planiranja. Pomoću ove opcije se menjaju pogledi na 3D sliku scene koja se modelira. Slika je prikazana zajedno sa sijalicama i veštačkim osvetljenjem koje one daju. 


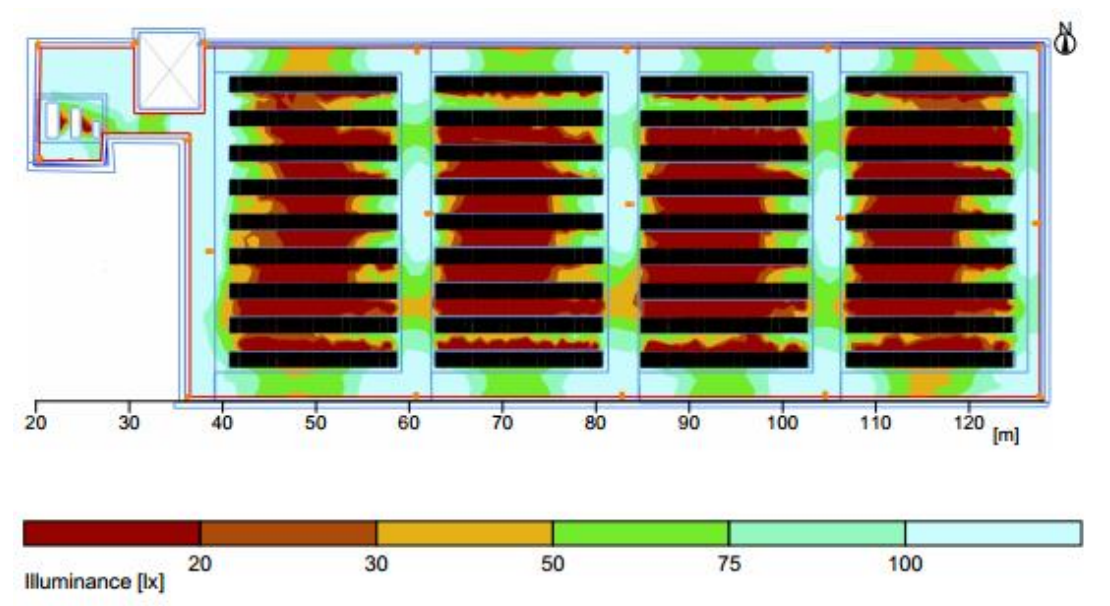

\begin{tabular}{|c|c|c|}
\hline $\begin{array}{l}\text { General } \\
\text { Calculation algorithr } \\
\text { Height (phot.centre) } \\
\text { Maintenance factor }\end{array}$ & & $\begin{array}{l}\text { Average indirect fraction } \\
7.11 \mathrm{~m} \\
0.80\end{array}$ \\
\hline $\begin{array}{l}\text { Total luminous flux } \\
\text { Total power } \\
\text { Total power per are }\end{array}$ & $\left.m^{2}\right)$ & $\begin{array}{l}463980.00 \mathrm{Im} \\
3729.7 \mathrm{~W} \\
1.02 \mathrm{~W} / \mathrm{m}^{2}\left(1.94 \mathrm{~W} / \mathrm{m}^{2} / 100 \mathrm{~lx}\right)\end{array}$ \\
\hline Evaluation area 1 & $\begin{array}{l}\text { Reference plane } 1.1 \\
\text { Horizontal }\end{array}$ & \\
\hline $\begin{array}{l}\text { Em } \\
\text { Emin } \\
\text { Emin/Em (Uo) } \\
\text { Emin/Emax (Ud) } \\
\text { Position }\end{array}$ & $\begin{array}{l}52.6 \mathrm{Ix} \\
1.1 \mathrm{Ix} \\
0.02 \\
0.01 \\
0.31 \mathrm{~m}\end{array}$ & \\
\hline
\end{tabular}

Type No.lMake

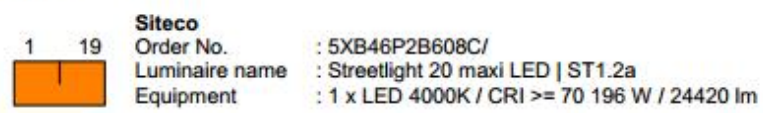

Slika 3. Raspored osvetljenja i osnovne informacije o osvetljenju.

\section{TEHNO-EKONOMSKA ANALIZA}

Da bi se uradila tehno-ekonomska analiza, potrebno je odrediti (proceniti) troškove, koji se odnose na kupovinu i ugradnju svih komponenti razmatranog sistema, kao i troškove vezane za održavanje sistema.

Prva komponenta, koja će se posmatrati je SUNNY WEBBOX, uređaj koji košta $560 €$. Na njega se može priključiti 10 invertora, koliko postoji na solarnoj elektrani.

$\mathrm{Za}$ video nadzor ove solarne PV elektrane jeodabrano 25 $8 \mathrm{Mp}$ bullet vodootpornih kamera sa ICR senzorom dometa $80 \mathrm{~m}$. Detektuju upad u zonu, prelazak preko zamišljene linije i lice. Zaštita kamere od spoljašnjih uslova je IP67. Cena jedne kamere je $190 €$, a ukupna cena je $4.750 €$. Pored toga, potrebna su 2 DVR čitača sa po 16 izlaza i sa kablovima za napajanje i razdlenicima po ceni od 225 $€ /$ kom. Ukupna cena video nadzora je $5.200 €$.

Za ograđivanje postrojenja je korištena 3D panelna ograda. Svi ogradni elementi su izrađeni od toplo pocinkovanog čelika i plastificirani poliesterom. Panel dimenzije 2500 $\mathrm{mm} \times 2030 \mathrm{~mm}$ ima cenu od 26,3 $€ / \mathrm{kom}$. Debljina žice je 4 $\mathrm{mm}$. Pored panelnih ograda, potrebno je ugraditi i noseće stubove, koji su takođe pocinkovani i plastificirani. Stubovi dimenzije $50 \mathrm{~mm}$ x $50 \mathrm{~mm}$ x $2050 \mathrm{~mm}$ imaju cenu od 14,7 $€ /$ kom. Za ograđivanje (rad) je potrbno platiti još $5.945 €$.

Na kraju, korišteno je 19 LED reflektora. Cena jednog reflektora je $600 €$. Sa ugradnjom pametnog sistema i napajanja preko sopstvenog solarnog panela, te cene idu i do $1.000 €$. Ako se uzmu klasične LED sijalice cena za 19 sijalica bi bila $11.400 €$. Kada se sve sabere, troškovi informacionog sistema i bezbedonosnog sistema su $23.105 €$.

S obzirom da solarna elektrana ima 648 panela i 10 invertora, a da je prosečna cena FN panela oko $200 €$, invertora $2.200 €$, te uz dodate troškove za kablove i razvodno postrojenje, ukupna ulaganja u FN elektranu se mogu proceniti na oko $170.000-180.000 €$.

Sistem za zaštitu od krađe i informacioni sistem je oko $11 \%$ od ukupnog ulaganja u elektranu, što je s obzirom na vrednosti imovine (poseda i opreme) i koji se treba nadgledati i sačuvati, investicija u koju vredi uložiti. U tabeli 2 se nalazi jedinična cena i količina opreme koju treba uložiti u sigurnosni i informacioni sistem solarne elektrane.

Tabela 2. Troškovi za informacioni i bezbedonosni sistem

\begin{tabular}{|c|c|c|c|}
\hline Vrsta opreme & $\begin{array}{c}\text { Jedinična } \\
\text { cena }\end{array}$ & Količina & $\begin{array}{c}\text { Ukupna } \\
\text { cena }\end{array}$ \\
\hline $\begin{array}{c}\text { SUNNY WEBBOX } \\
\text { komunikacijski uređaj }\end{array}$ & $560 €$ & 1 & $560 €$ \\
\hline $\begin{array}{c}\text { HIKVISION kamera za } \\
\text { nadzor }\end{array}$ & $190 €$ & 25 & $4750 €$ \\
\hline DVR čitač & $225 €$ & 2 & $450 €$ \\
\hline 3D panelna ograda & $41 €$ & 145 & $5945 €$ \\
\hline LED reflektor siteco & $600 €$ & 19 & $11400 €$ \\
\hline
\end{tabular}




\section{ZAKLJUČAK}

Zbog velikih početnih ulaganja i izolovanosti solarnih farmi, čija je pozicija obično uslovljena mestom koje je pogodno za građenje, potrebno je pronaći adekvatan sistem zaštite i upravljanja.

Što se tiče informacionog i upravljačkog dela, obično se koriste inofrmacioni uređaji istog proizvođača ili drugog proizvođača koji su kompatibilni sa invertorima na solarnoj farmi. Ti uređaji stalno prikupljaju podatke i šalju ih osobama zaduženim za nadzor. Ulaganje u ove sisteme je isplativo jer pomoću njih možemo otkriti grešku u radu neke komponenete solarne elektrane i reagovati u što kraćem roku kako bi se izbegli eventualni gubici zbog nepravilnog rada. Još jedna prednost ulaganja $\mathrm{u}$ informacione sisteme je mogućnost daljinske promene parametara svih invertora elektrane.

Bezbedonosni sistemi su bitan faktor u zaštiti solarnog postrojenja i njegovih objekata. Koriste se razne vrste ograda sa perimetrijskim zaštitama, te električne ograde visokih voltaža sa visokim stepenom odvraćanja. Moguće je korištenje sistema kartica za ograničavanje pristupa koje obezbeđuju velike sistem od više celina od neovlaštenog upada.

Pored ograđivanja farmi, neizostavan deo zaštite je video nadzor koji može biti pomoću analognog i IP video nadzora. IP video nadzor predstavlja sistem video nadzora kod kog je moguće pregledati snimke ili gledati uživo snimak preko mreže (LAN ili Internet). To je velika prednost jer nam daje mogućnost mobilnosti. Iako je IP video nadzor skuplji od analognog, IP video nadzor je bolje rešenje i isplativije na duže staze. Zaštite koje se ređe koriste jesu zaštite mikrotalasima i infracrvenim zracima koji rade na principu predajnik-prijemnik. Zbog mogućnosti nepravilnog rada pri nepovoljnim vremenskim uslovima i potrebe za izborom kvalitetnijih komponeneti koji su skuplje, ova zaštita se koristi kada postoji potreba za visokim nivoom sigurnosti. U takvim situacijama se pored video nadzora i ograđivanja, koriste i visokokvalitetna zaštita miktrotalasima. Različite kombinacije ovih zaštita se koriste u skladu sa potrebama terena i ekonomskim mogućnostima investitora. Najčešće se koristi kombinacija električne ograde i video nadzora.

$\mathrm{Za}$ proračun osvetljenja, koriste se program za dizajniranje osvetljenja kojih ima na tržištu preko 30 od različitih kompanija. S obzirom na potrebe ovog projekta i uvažavajući osobine ovih programa, izabrana su 4 programa: Relux, DIALux, AGI32 i Radiance za uporednu analizu kako bi se izabrao najpogodniji program za dizajniranje osvetljenja solarnog postrojenja. AGI32 se ispostavio kao program koji daje najtačnije rezultate, ali je zbog plaćanja licence za korištenje, bio nepogodan za ovaj proračun.
Radiance je takođe davao izuzetno tačne rezultate $u$ proračunima po istraživanjima, ali je zbog interfejsa koji je komplikovan za korištenje i "open source" koncepta isključen iz užeg izbora. Zbog toga što je odnos tačnosti rezultata i brzine obrade podataka i simulacije bolji kod Relux-a u odnosu na DIALux, Relux je program koji je izabran za dizajniranje osvetljenja solarne elektrane.

$\mathrm{Na}$ kraju rada, detaljno je objašnjen postupak rada $\mathrm{u}$ Relux-u, od uvoza crteža elektrane iz Aecosim-a u Relux preko crtanja objekata u 3D-u koji bi mogli bacati senku na osvetljena područja do izbora sijalica, kalkulacije i izrade izveštaja u .pdf format. Izabrano je 19 LED sijalica koje troše po 196W sa solarnim panelom na svom stubu.

Da zaključimo, solarno ulično osvetljenje nije usvojeno do sada kao pouzdana zamena tradicionalnom. Danas, uz pomoć pametne tehnologije, u mogucnosti smó da pretvorimo solarno ulično osvetljenje u standardizovano rešenje za osvetljenje, demistifikujući njegovu lošu reputaciju iz prošlosti. Investicija u pametno solarno ulično osvetljenje je zaista vredna i u budućnosti će se isplatiti.

\section{LITERATURA}

[1] https://www.downloads.siemens.com/downloadcenter/Download.aspx?pos=download\&fct=ge tasset\&id1=A6V10594616

[2] https://issuu.com/peter.byrne1000/docs/dissertation_peter_byrne_-_publis

[3] https://reluxnet.relux.com/en/

\section{Kratka biografija:}

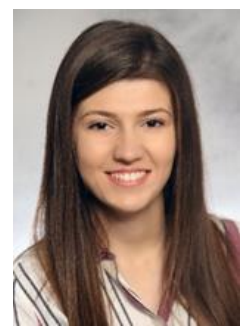

Aleksandra Stevanović rođena je 1994. godine u Bijeljini. Fakultet tehničkih nauka, studijski program Energetika, elektronika i telekomunikacije upisala je školske 2013/2014 godine. Na studijama se opredelila za smer Elektroenergetski sistemi i diplomirala 2018. god. Master studije je upisala školske 2018/2019. god. na studijskom programu Eneregetika, elektronika i telekomunikacije, modul Elektroenergetika -Distribuirani elektroenergetski resursi (MAS)

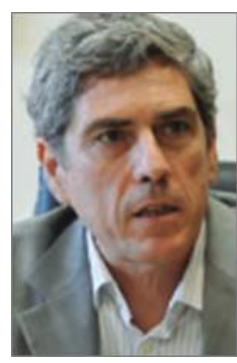

Vladimir Katić rođen je 1954. godine u Novom Sadu. Doktorirao je na Univerzitetu u Beogradu 1991. godine. Od 2002. godine je redovni profesor Univerziteta $\mathrm{u}$ Novom Sadu. Na Fakultetu tehničkih nauka sada je Prodekan za finansije i razvoj (od 1998 god.). Oblasti interesovanja su energetska elektronika, obnovljivi izvori električne energije, električna vozila i kvalitet električne energije. 